\title{
Ontogeny of electric organ and electric organ discharge in Campylomormyrus rhynchophorus (Teleostei: Mormyridae)
}

\author{
Linh Nguyen ${ }^{1,2} \cdot$ Victor Mamonekene $^{3} \cdot$ Marianne Vater $^{4} \cdot$ Peter Bartsch $^{5} \cdot$ Ralph Tiedemann $^{1} \cdot$ Frank Kirschbaum $^{2}(\mathbb{C}$
}

Received: 24 January 2019 / Revised: 9 February 2020 / Accepted: 15 February 2020 / Published online: 28 February 2020

(c) The Author(s) 2020, corrected publication 2021

\begin{abstract}
The aim of this study was a longitudinal description of the ontogeny of the adult electric organ of Campylomormyrus rhynchophorus which produces as adult an electric organ discharge of very long duration (ca. $25 \mathrm{~ms}$ ). We could indeed show (for the first time in a mormyrid fish) that the electric organ discharge which is first produced early during ontogeny in 33-mm-long juveniles is much shorter in duration and has a different shape than the electric organ discharge in 15-cm-long adults. The change from this juvenile electric organ discharges into the adult electric organ discharge takes at least a year. The increase in electric organ discharge duration could be causally linked to the development of surface evaginations, papillae, at the rostral face of the electrocyte which are recognizable for the first time in 65-mm-long juveniles and are most prominent at the periphery of the electrocyte.
\end{abstract}

Keywords Weakly electric fish $\cdot$ Development $\cdot$ Electric organ discharge $\cdot$ Electric organ $\cdot$ Electrocyte features

\section{Abbreviations \\ EO Electric organ \\ EOD Electric organ discharge}

Electronic supplementary material The online version of this article (https://doi.org/10.1007/s00359-020-01411-z) contains supplementary material, which is available to authorized users.

Frank Kirschbaum

frank.kirschbaum@staff.hu-berlin.de

1 Unit of Evolutionary Biology/Systematic Zoology, Institute of Biochemistry and Biology, University of Potsdam, Karl-Liebknecht-Str. 24-25, Haus 26, 14476 Potsdam-Golm, Germany

2 Unit of Biology and Ecology of Fishes, Faculty of Life Sciences, Humboldt University of Berlin, Philippstr. 13, Haus 16, 10115 Berlin, Germany

3 Ecole Nationale Supérieure d'Agronomie et de Foresterie, Université Marien Ngouabi, B.P. 69, Brazzaville, Republic of Congo

4 Unit of General Zoology, Institute of Biochemistry and Biology, University of Potsdam, Karl-Liebknecht-Str. 24-25, Haus 26, 14476 Potsdam-Golm, Germany

5 Leibniz-Institute for Evolution and Biodiversity Science, Museum fuer Naturkunde Berlin, Invalidenstr. 43, 10115 Berlin, Germany

\section{Introduction}

The speciose weakly electric gymnotiform and mormyrid fishes (Froese and Pauly 2008) possess an active sensory system comprising electric organs (EOs) and electroreceptors (e.g., Moller 1995). This system is used for electrolocation (e.g., Bullock and Heiligenberg 1986; von der Emde 1992, 1999, 2006) and electrocommunication (e.g., Kramer 1990).

The electric organ discharges (EODs) are very diverse both in gymnotiform (e.g., Crampton 2006; Crampton et al. 2013) and mormyrid fishes (e.g., Hopkins 1981; Lamanna et al. 2016). Early investigations on the ontogeny of the EOs suffered from a lack of embryological material and juveniles (Keynes 1961; Szabo 1960, 1966). The reproduction of these weakly electric fishes is based on the imitation of rainy season conditions (Kirschbaum 1975) and opened the way for detailed ontogenetic descriptions (Kirschbaum and Schwassmann 2008; Kirschbaum 1977, 1981). This led to the discovery of larval electric organs (Kirschbaum 1977).

African mormyrid fish possess a larval EO found in the deep lateral muscle and an adult electric organ located in the caudal peduncle. The EOD of the larval organ is biphasic, with a large head-positive phase and a smaller, longer lasting head-negative phase; the total duration is ca. $3 \mathrm{~ms}$ (Kirschbaum and Westby 1975). The first description of such a larval electric organ was performed on Pollimyrus isidori 
(Westby and Kirschbaum 1977). Similar larval EODs were found in M. rume proboscirostris and in Campylomormyrus cassaicus (Schugardt 1997), in P. castelnaui and P. marianne (Baier et al. 2006), in Marcusenius macrolepidotus (Werneyer and Kramer 2006), in Petrocephalus soudanensis (Kirschbaum, unpublished results), in Campylomormyrus compressirostris, C. tamandua, C. tshokwe and in three morphs of Paramormyrops sp. "magnostipes" (Nguyen, unpublished results). The larval EOD is not species specific and cannot be used for species identification.

The larval electrocytes are located in the myomeres of the deep lateral muscle and border muscle fibers (Kirschbaum 1977, 1981). They contain many partly disorganized myofibrils and a caudad stalk which receives the innervation (Denizot et al. 1978). The anatomy of the larval electrocytes, first discovered in P. isidori (Kirschbaum 1981), was found similar in other mormyrid species, i.e., Hyperopisus bebe, M. rume, and Mormyrops deliciosus (Kirschbaum 1995). Therefore, the larval electric organ of the mormyrids is a very conservative structure. It degenerates early in ontogeny (Kirschbaum 1981) after the differentiation of the adult EO.

The adult electric organ in the caudal peduncle has been repeatedly described (e.g., Koelliker 1849; Schlichter 1906; Szabo 1958; Bennett 1971; Bruns 1971; Bass 1986). It represents a very complex structure which develops in ontogeny later than the larval EO. At a certain stage, both organs coexist and are both active (Westby and Kirschbaum 1978). In $P$. isidori the discharges of the two organs do not superimpose, instead, the activity of the larval organ is separated from the following activity of the adult organ by about $0.6 \mathrm{~ms}$ (Westby and Kirschbaum 1978; Baier et al. 2006). Therefore, changes in amplitude of both organs and the disappearance of the activity of the larval organ are easily observable. In contrast, discharges of both electric organs are superimposed during their co-existence in M. macrolepidotus (Werneyer and Kramer 2006), M. rume proboscirostris and $C$. cassaicus (Schugardt 1997), P. soudanensis (Kirschbaum, unpublished results), C. compressirostris, $C$. tamandua, $C$. tshokwe, and in three morphs of the Paramormyrops sp. "magnostipes" (Nguyen, unpublished results), rendering the activities of the two respective organs more difficult to disentangle. This period of co-existence lasts about 40 days in P. isidori (Westby and Kirschbaum 1978) and about 3 weeks in P. castelnaui and P. marianne (Baier et al. 2006).

The complex structure and diversity of the adult EO (e.g., Bass 1986) is matched by a high diversity of EOD waveforms (e.g., Hopkins 1981; Bass 1986; Lamanna et al. 2016). The EOD can serve as prezygotic isolation mechanism and can be used for species identification.

EODs are quite short (in the range of several $100 \mu$ s up to about $1 \mathrm{~ms}$ ) and-once the adult EOD is established during early ontogeny in the juvenile fish-it will not further change during ontogeny up to adulthood. Exceptions from this rule are the Type I and Type III morphs of Paramormyrops sp. "magnostipes" (Arnegard et al. 2005), where some change in the shape of the EOD occurs during ontogeny. Furthermore, deviating from this pattern is the ontogeny of Campylomormyrus numenius, a species with a very long EOD of about $25 \mathrm{~ms}$ duration (Paul et al. 2015). Juvenile fish of about $10 \mathrm{~cm}$ total length produce an EOD which is considerably shorter and different in shape, relative to that of the adult. A complete description of the EOD ontogeny of this species could so far not be performed due to the lack of captive breeding. The sister species of $C$. numenius is $C$. rhynchophorus (Feulner et al. 2008), which also produces an adult EOD of about $25 \mathrm{~ms}$ duration. As this species can be bred quite easily in captivity (Nguyen et al. 2017), we choose this fish for a longitudinal study on the ontogeny of the EOD. We could indeed show, that the adult EOD changes during ontogeny over several months considerably both in shape and duration, a pattern which so far has never been described in any mormyrid fish.

\section{Materials and methods}

\section{Animals and breeding}

The $C$. rhynchophorus pair that gave origin to the developmental stages described in this paper originated from the Congo River from the Kinshasa region. It was purchased via a wholesale dealer in Germany (near Frankfurt) and it grew up from juvenile size up to the size of sexual maturity (ca. $15 \mathrm{~cm}$ ). Imitation of rainy season conditions consisted of lowering the water conductivity in the experimental tanks. Subsequently the fish developed ripe gonads and spawned repeatedly. Details of the breeding are described in Nguyen et al. (2017).

The parental fish were fed twice daily with live Chaoborus (Corethra) larvae in the morning and live chironomids in the evening. Frozen food was supplied when live food was not available.

The inseminated eggs were put into Petri dishes $(\phi=8.6 \mathrm{~cm}, 1.5 \mathrm{~cm}$ high) with various densities between 5 and 50 eggs per dish. At one day postspawning, the eggs were inspected for viable embryos and unfertilized eggs were discarded. Only the fertilized eggs were selected for further incubation in the water of the breeding tank. Incubation was performed in an incubator at $27 \pm 0.5^{\circ} \mathrm{C}$ or at room temperature $\left(23-27^{\circ} \mathrm{C}\right)$. After hatching, free embryos were transferred into new Petri dishes and tap water (conductivity ca. $700 \mu \mathrm{S} / \mathrm{cm} ; \mathrm{pH}$ ca. 7.4 ) was added gradually to the water of the breeding tank to rear them. One week after hatching, the free embryos [(terminology after Balon (1975)] could be raised in tap water. 15-mm-long larvae up to 40-mm-long 
juveniles were raised in plastic boxes $(1 \mathrm{~L})$. Afterwards they were moved to small aquaria $(12 \mathrm{~L})$.

The fry were fed with newly hatched Artemia nauplii from the beginning of exogenous feeding (i.e., at day eight after hatching) up to about 30- to 40-mm-long juveniles. Thereafter, small chironomid larvae were supplied in addition. Larger juveniles were fed as the parents.

Five specimens were raised individually after the first EOD measurement to follow their ontogeny with regard to both morphology and EOD (after the beginning of exogenous feeding). Additional fish were raised in community tanks and they were checked regularly for growth and EOD development and compared to the individually raised ones. A few of these additional fish were killed for histological investigation of the EO: 18-mm-long fish for the characterization of the larval electric organ; juveniles between 32 and $36 \mathrm{~mm}$ long at the transition from the larval to the juvenile EOD; juveniles between 65 and $80 \mathrm{~mm}$ length characterized by an EOD of increased duration (ca. 9-37 ms duration); adult fish with an EOD duration of about $25 \mathrm{~ms}$.

\section{Photography}

The specimens used for the morphological description were anesthetized with MS 222. Recovery from the anesthetic took a few minutes. Photos were taken with a digital camera Canon EOS 350D or Canon EOS 100D.

\section{Oscilloscope recordings}

In order to analyze species-specific EOD characteristics, the fish were put in plastic aquaria of different size filled with water of the keeping tank (in general tap water of conductivity values between 700 and $900 \mu \mathrm{S} / \mathrm{cm}$, temperature: $24-26^{\circ} \mathrm{C}$ ); the sizes of the recording tank comprised $11 \times 11 \mathrm{~mm}$ for the larvae, $7 \times 5 \mathrm{~cm}$ for the smaller, and $13 \times 15 \mathrm{~cm}$ for the larger juveniles. Water level was adjusted according to the size of the fish. The EOD of the 8-day-old larva was measured in a plastic pipette. The EOD was also recorded in a clay tube in order evaluate whether the plastic aquaria had some influence on the shape of the EOD, which was not the case. The container featured a compartment adjustable in size that prevented the fish from freely swimming during the measurements. Steel electrodes were positioned at the rostral and caudal end of the fish - the positive electrode was positioned next to the head. The EOD waveforms were displayed and recorded by a Tektronix TDS 3012B digital phosphor oscilloscope (sampling rate: $10 \mathrm{kHz}$; bit vertical resolution) with a Tektronix ADA 400A differential preamplifier (variable gain from $0.1 \times$ up to $100 \times$; bandwidth $100 \mathrm{~Hz}-1 \mathrm{MHz}$ ). The oscilloscope and preamplifier were
AC coupled. The EOD data were transferred onto the hard drive of a computer via floppy disks. Per individual, one representative EOD, normalized to $1 \mathrm{~V}$, was analyzed.

The start and end points of whole EODs were defined as the points where the amplitudes reached $2 \%$ of the total discharge amplitude. The start and endpoints of each phase within the EOD were determined at the crossing points at the zero line (Fig. 1). Software running under R (see supplementary material) was used to calculate duration and amplitude of each phase and the whole signal.

\section{Histological techniques}

The EOs were subjected to anatomical examinations via light microscopy. For the preparation of the histological slides, the fish were euthanized by an overdose of ethylenglycolmonophenylether and the caudal peduncle was cut off. The tissue was fixed by immersion in $4 \%$ formalin in the case of small fish or in $10 \%$ formalin in larger fish. Fixed tissue of larger fish was decalcified with 7.5\% EDTA ( $\mathrm{pH}$ 7.4). Dehydration and embedding in paraffin followed established protocols (Mulisch and Welsch 2010). The EO of each specimen was sectioned serially at 4-6 $\mu \mathrm{m}$ either in the transverse or the sagittal plane using a Leica 2035 Biocut microtome. Sections were mounted on glycerin/albumin-coated slides. Following deparaffinization and rehydration, sections were stained with Azan or HE (Mulisch and Welsch 2010), dehydrated and coverslipped with DePeX mounting medium (Sigma-Aldrich). Sections were investigated with a Leica microscope DM4000B. Pictures were taken and processed by using the Leica DFC 480 camera together with the Leica IM software version 4.0 .

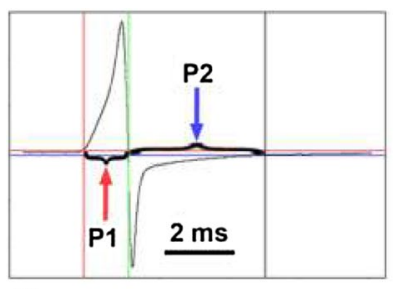

a

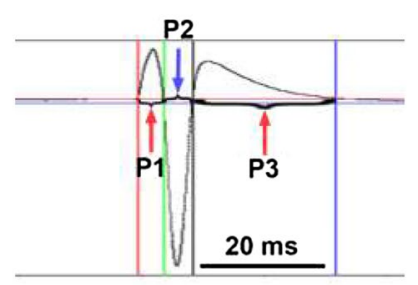

b

Fig. 1 Two electric organ discharge types (EODs) of Campylomormyrus rhynchophorus which occur during ontogeny, a biphasic EOD (a, from a 65-mm-long juvenile) and a triphasic EOD from a 155-mm-long juvenile (b), are selected to illustrate how the duration of the different EOD phases were calculated 


\section{Results}

\section{Ontogeny of morphology and of the electric organ discharge}

The first EOD activity was detected in 8-day-old, ca. 10-mm-long free embryos (EOD data not shown here). This biphasic EOD resembles the activity of the larval electric organ already described in other mormyrid species, e.g., in Pollimyrus species (Westby and Kirschbaum 1978). The larval EOD of a 18-mm-long larva is shown in Fig. 2a1. This larva still possesses remnants of the
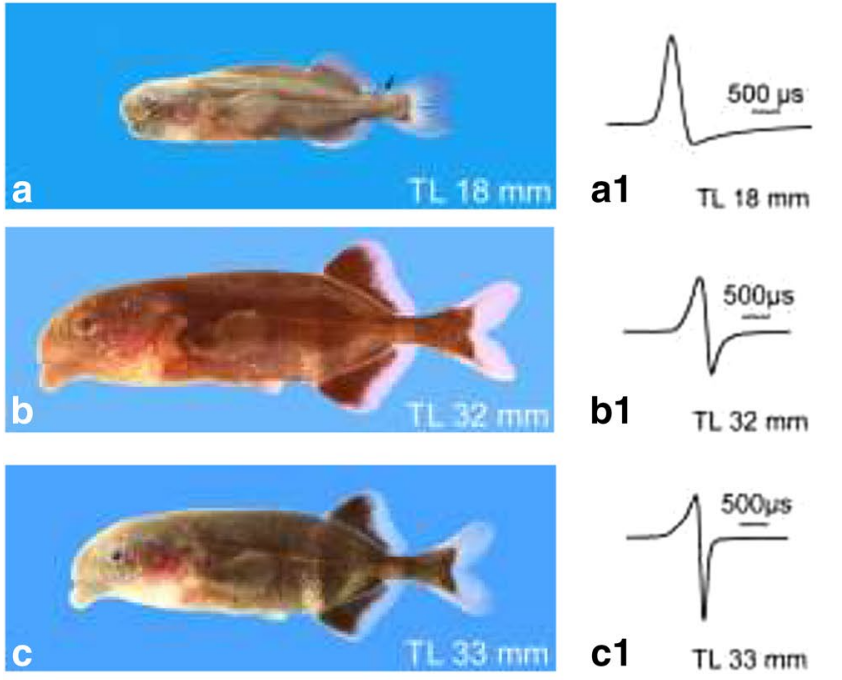

b1
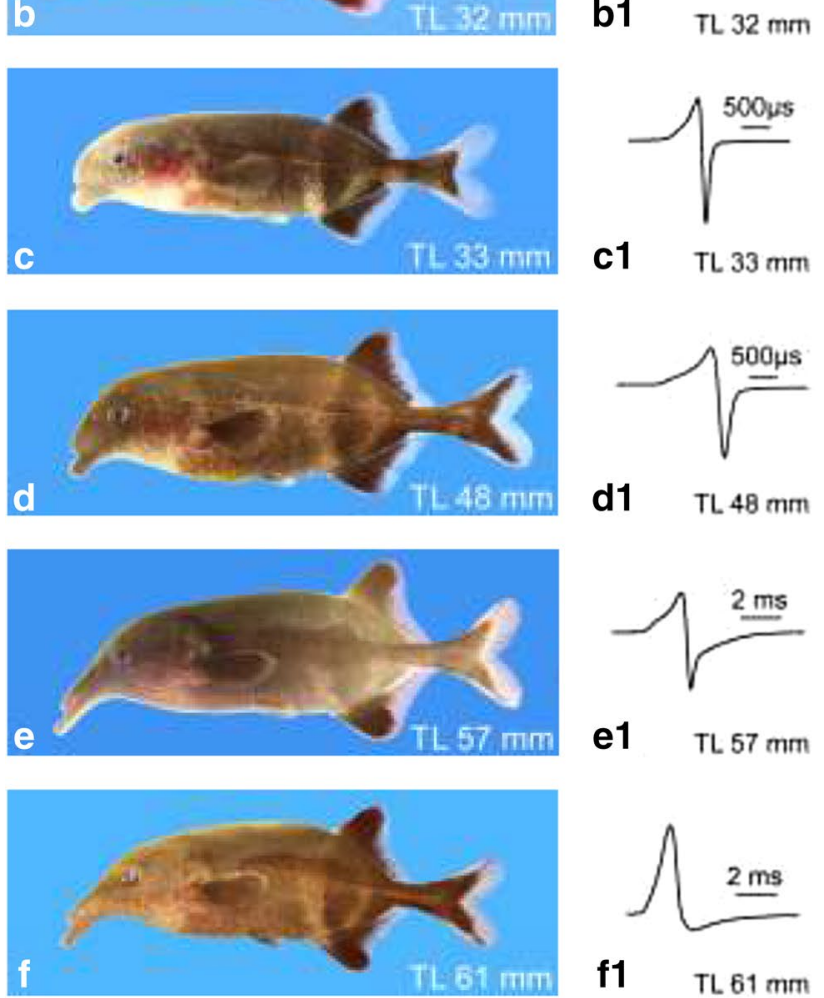

Fig. 2 Ontogeny of morphology and electric organ discharge (EOD) of Campylomormyrus rhynchophorus. a A 18-mm-long larva with remnants of the larval fin fold at the caudal peduncle (arrow). b-k Juveniles of various sizes showing the change in pigmentation, the allometric growth of the snout and the increase in body height during development. I Adult female. a1 Shows the larval EOD, b1 the transi- embryological fin fold (Fig. 2a); the Campylomormyrustypical snout is not yet developed. A 32-mm-long juvenile (Fig. 2b) produced an EOD (Fig. 2b1) with a first change in the EOD shape: the amplitude of the head-negative phase has started to increase. This is the first indication that the adult electric organ has started to become functional. A 33-mm-long juvenile (Fig. 2c) produced a biphasic EOD where the amplitude of the head-negative phase was about twice as high as that of the head-positive phase (Table 1, Fig. 2c1). We have termed this EOD the "juvenile EOD" because it is produced by the juvenile fish and is different from the EOD found in adults. This EOD type persists for several weeks. At around $48 \mathrm{~mm}$ length, the duration of
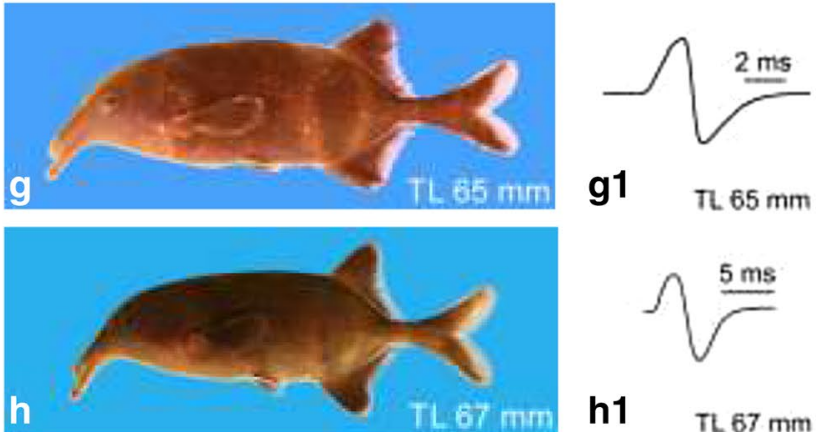

h1

TL $67 \mathrm{~mm}$
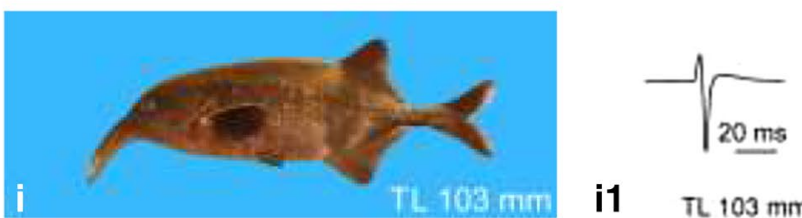

i1

TL $103 \mathrm{~mm}$
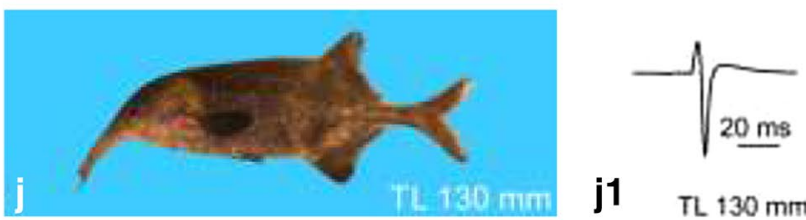

j1

$\mathrm{TL} 130 \mathrm{~mm}$
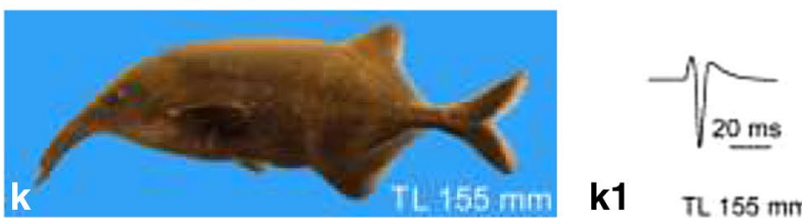

k1

$\mathrm{TL} 155 \mathrm{~mm}$

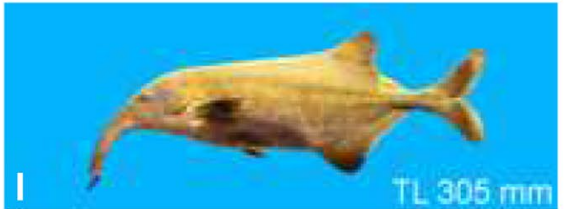

11

TL $320 \mathrm{~mm}$

tional stage with both, the larval and the adult EO active. c1 EOD of the adult EO alone; we termed this EOD the juvenile EOD, because it is produced by a juvenile fish. Note that the EODs are shown at different time scales to better demonstrate the shape of the EOD. Some data on the morphological and EOD development had already been published in Nguyen et al. (2017) 
Table 1 Change of amplitude (Amp) and duration (Dur) during the electric organ discharge (EOD) ontogeny in Campylomormyrus rhynchophorus

\begin{tabular}{llllllllll}
\hline Size of fish & Amp P1 (v) & Amp P2 (v) & Amp P3 (v) & Amp P1/P2 & Amp P3/P1 & Dur P1 (ms) & Dur P2 (ms) & Dur P3 (ms) & Total dur (ms) \\
\hline $33 \mathrm{~mm}$ & 2.12 & 3.96 & - & 0.54 & - & 0.75 & 0.25 & - & 1.00 \\
$48 \mathrm{~mm}$ & 1.22 & 2.34 & - & 0.52 & - & 0.98 & 0.91 & - & 1.89 \\
$57 \mathrm{~mm}$ & 1.15 & 1.59 & - & 0.72 & - & 2.05 & 2.82 & - & 4.87 \\
$61 \mathrm{~mm}$ & 4.30 & 0.78 & - & 5.51 & - & 1.65 & 6.21 & - & 7.86 \\
$65 \mathrm{~mm}$ & 1.31 & 1.21 & - & 1.08 & - & 1.93 & 4.90 & - & 6.83 \\
$67 \mathrm{~mm}$ & 0.85 & 1.18 & 0.09 & 0.72 & 0.11 & 2.88 & 4.26 & 29.46 & 36.60 \\
$103 \mathrm{~mm}$ & 0.87 & 2.31 & 0.23 & 0.38 & 0.26 & 3.81 & 4.84 & 32.36 & 41.01 \\
$130 \mathrm{~mm}$ & 0.36 & 0.78 & 0.14 & 0.46 & 0.39 & 4.40 & 4.70 & 25.35 & 34.45 \\
$155 \mathrm{~mm}$ & 0.72 & 2.26 & 0.53 & 0.32 & 0.74 & 4.71 & 4.96 & 21.61 & 31.28 \\
$320 \mathrm{~mm}$ & 0.22 & 0.61 & 0.18 & 0.36 & 0.81 & 3.60 & 4.78 & 18.13 & 26.51 \\
\hline
\end{tabular}

For the different phases of the EOD, see Fig. 1

the juvenile EOD had slightly increased and the amplitude of the head-negative phase decreased compared to the amplitude of the head-positive phase (Table 1). Such an EOD of a $48 \mathrm{~mm}$ juvenile is shown in Fig. 2d1. The morphology of such a juvenile (Fig. 2d) shows that the Campylomormyrus-typical snout has started to develop. A 57-mm-long juvenile (Fig. 1e) showed an EOD with increased duration and a prolongation of the head-negative phase (Fig. 2e1; Table 1). Between the $57 \mathrm{~mm}$ juvenile and the $61 \mathrm{~mm}$ juvenile a considerable change in EOD shape occurs. The 61-mm-long fish produces an EOD with a large head-positive amplitude and a small headnegative phase of long duration (Fig. 2f1) (Table 1). This EOD shape generated by the adult electric organ resembles very much the shape of the larval EOD (Fig. 2a1), though the duration is much longer (nearly four times as long, Table 1). In a slightly longer juvenile (65 mm, Fig. $2 \mathrm{~g}$ ) the head-positive and head-negative phases are nearly of equal amplitude (Fig. 2g1; Table 1). This EOD type is still found in the $67 \mathrm{~mm}$ juvenile (Fig. 1h1), but the duration has slightly increased (Fig. 2h1). A second head-positive phase has started to appear in some specimens of this size. The amplitude of this head-positive phase continuously increased with size (Fig. 2i1, j1, k1) as seen in the 103, 130 and 155-mm-long juveniles (Fig. 1i-k; Table 1). Morphologically the 130 and 155 -mm-long juveniles already resemble very much the adult fish (Fig. 11).

In Fig. 3 the ontogeny of the EOD is shown at two different time bases, (1) with a fixed time scale in order to better illustrate the increase in duration (time scale $20 \mathrm{~ms}$; Fig. 3c-1) and (2) at variable time scale to facilitate EOD shape comparisons (Fig. 3c1-11). Figure 3a, a1 shows the larval EOD and Fig. 3b, 3b1 the transition between larval and adult EOD.

\section{Individual variation in the ontogeny of the electric organ discharge}

As shown in the preceding paragraph, the EOD of the adult electric organ changes continuously during ontogeny in both shape and duration, starting from the juvenile EOD in the $33 \mathrm{~mm}$ fish (Fig. 3c). Figure 4 shows overlays of EODs (Fig. 4a-h) from five individuals of the same developmental stage (except for the adult EOD, where only 3 specimens were measured) along the EOD ontogeny. The EODs of the individual fish are also shown (Fig. 4a1-h1) in order to illustrate the small difference between EODs of the individuals. Figure 4 starts with the larval EOD (Fig. 4a). Figure $4 \mathrm{~b}$ shows the earliest juvenile EOD. The EODs of the 52- to 59-mm-long juveniles are shown in Fig. 4c, c1. Biphasic EODs with approximately the same amplitudes of both phases are shown in Fig. 4d, d1, e, e1. Figure 4f, f1, g, g1 shows the EOD of juveniles of which the EOD resembles already very much the EOD of the adult fish (Fig. 4h, h1). Figure 4 demonstrates that there are only slight inter-individual differences in the shape of the EOD during ontogeny; inter-individual differences are most pronounced in 60- to 64-mm-long fish (Fig. 4 d, d1). Among specimens, a specific EOD type does not occur at exactly the same size, but rather within a size range of several mm (Fig. 4).

\section{Change in the duration of the different phases of the EOD during ontogeny}

As seen in the description of the ontogeny of the EOD (Fig. 2), the originally biphasic discharge changes both its shape and duration and finally develops into a triphasic EOD. Figure 5 shows which of the phases of the EOD contribute to the total duration of the EOD. The duration 


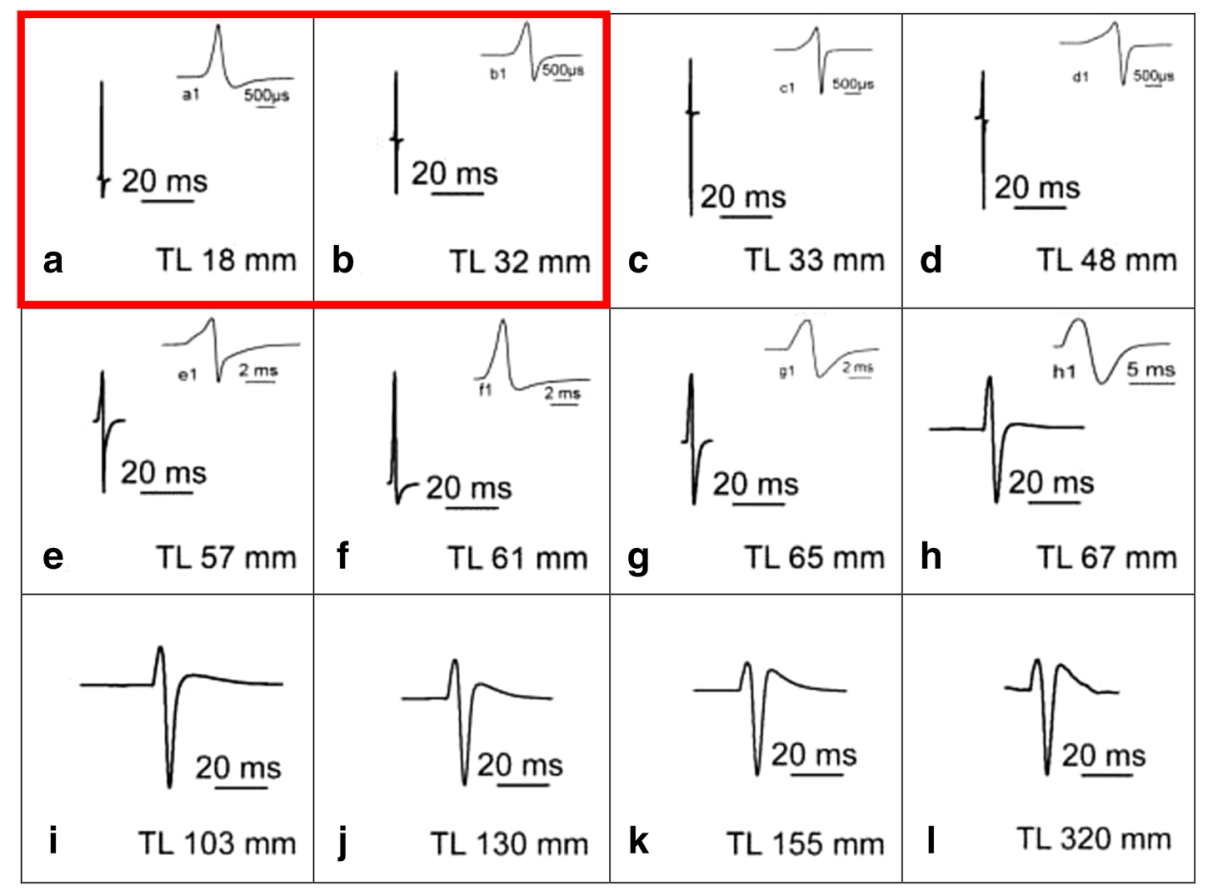

Fig. 3 Examples of electric organ discharge (EOD) types observed during ontogeny of Campylomormyrus rhynchophorus shown always at two different time scales to demonstrate (1) the change in duration of the EOD (20 ms time scale) and (2) to better show the shape of the EOD and its change during ontogeny (variable time scales, upper EOD). a Biphasic larval EOD. b Transition from larval to adult EOD; the activities of both EOs are superimposed. c First exclusive activity of the adult EO; termed juvenile EOD as it is produced by the juvenile fish. d, e Change of the juvenile EOD due to an increase in the duration of both phases. $\mathbf{f}$ Considerable decrease in the amplitude of the head-negative phase; this EOD shape resembles very much that of the larval EOD shown in $\mathbf{a} . \mathbf{g}, \mathbf{h}$ Change into a biphasic EOD of longer duration than before. i A triphasic EOD has developed due to the occurrence of a second head-positive phase. The amplitude of this phase continuously increases with the growth of the fish $(\mathbf{j}, \mathbf{k}, \mathbf{l}) . T L$ total length. Some data on the EOD ontogeny had already been published in Nguyen et al. (2017)

replaced by a mass of loose connective tissue (Fig. 6c). The larval electrocytes (Fig. 6c) are thicker than the neighboring muscle fibers (Fig. 6d) and-in contrast to the more densely stained muscle fibers-they possess a caudal extension, a stalk receiving the innervation (Fig. 6c).

\section{Adult electric organ}

The adult electric organ is situated in the caudal peduncle starting at the level of the caudal end of the dorsal fin and terminates before the beginning of the caudal fin (Fig. 6b). It is composed of four columns of in parallel arranged electrocytes, two ventral and two dorsal ones. Each electrocyte is enclosed in a compartment of loose connective tissue. As analyzed in serial sagittal sections, the main stalk system of the electrocytes of the adult organ in C. rhynchophorus is situated on the caudal face of the electrocyte (Fig. 8a). Figure 7 shows the branching type in $C$. rhynchophorus at various ontogenetic stages in cross sections of the EO. The main stalk of a $30 \mathrm{~mm}$ larva at the beginning of the activity of the adult EO is seen in Fig. 7a. One branch of the stalk extends dorsally and another one ventrally. From these main 


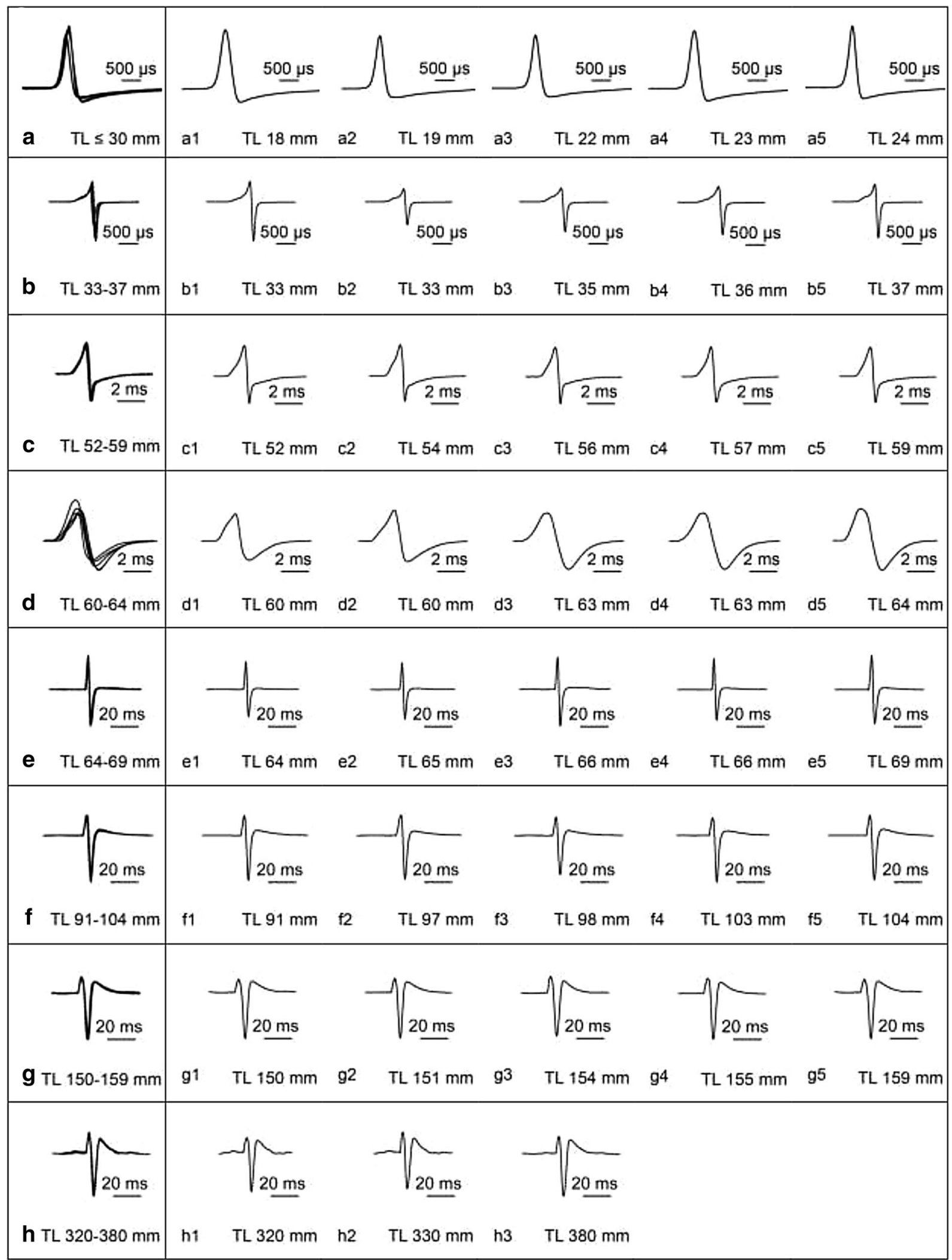

Fig. 4 Overlay plots of electric organ discharges (EODs) recorded from five, respectively, three different specimens (h) grouped together according to total length and developmental stage in Campylomormyrus rhynchophorus. In addition to the overlay plots the individual
EODs are shown as well. a, b, and $\mathbf{d}$ show slight individual variations in EOD shape, whereas in $\mathbf{c}, \mathbf{e}-\mathbf{h}$ virtually no individual variations in the shape of the EOD did occur. Some data on the EOD ontogeny had already been published in Nguyen et al. (2017) 


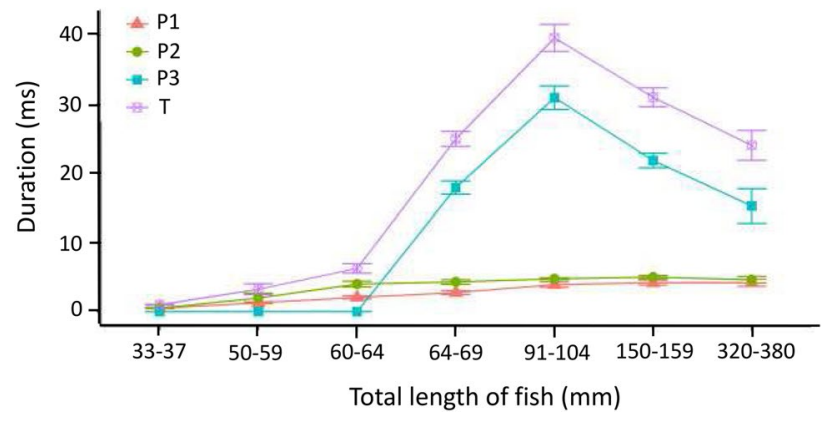

Fig. 5 Duration of the different phases of the adult electric organ discharge (EOD) during ontogeny in Campylomormyrus rhynchophorus. The large increase in the overall duration of the EOD is brought about by the increase in the duration of the second head-positive phase; the total duration of this phase decreases once the juveniles have reached a size of about $10 \mathrm{~cm}$. Concerning the different EOD phases, see Fig. 1. Mean and standard deviation are shown

branches, additional big branches extend laterally in both directions. In the $34 \mathrm{~mm}$ juvenile (Fig. 7b), a similar branching pattern is observed. In addition, it can be seen in this figure that the main stalk approaches the median line and neural tube of the fish; thus the electric nerves innervating the main stalk do not reach very far to the electrocyte. In the $65 \mathrm{~mm}$ juvenile (Fig. 7c), the branching pattern of the main stalk is more distinctive than in the younger fish. In the $71 \mathrm{~mm}$ juvenile, the finer branching pattern of the stalk system becomes apparent (Fig. 7d) (Table 2).

The four columns of the adult EO contain a variable number of electrocytes in mormyrids (see e.g., Paul et al. 2015). In C. rhynchophorus the number of electrocytes varies between 42 and 52 per column (Table 3). The table also shows that there is no significant increase in the number of electrocytes during early ontogeny.

The electrocytes extend from the dorsal to the ventral part of the column (Fig. 7a, c, d). However, there are a few irregularities in the alignment of the electric cells: some electrocytes do not extend over the whole width of the column, as demonstrated in Fig. 8b, d, f.

Surface evaginations of the electrocytes, so-called papillae, were described in many species (Bennett 1970, 1971; Schwartz et al. 1975; Bass et al. 1986). They are thought to contribute to an elongation of the EOD. We also found papillae in C. rhynchophorus. Figure 9 shows micrographs of electrocytes from the central part of the EO at various developmental stages. For each stage, peripheral and central regions of the electrocyte are compared. In the $36 \mathrm{~mm}$ juvenile (i.e., at the time when the adult $\mathrm{EO}$ begins to function), very small surface evaginations are seen both at the periphery (Fig. 9a) and the central part of the electrocytes (Fig. 9b), which seem to comprise structures later developing into papillae. Distinct papillae are found in the $65 \mathrm{~mm}$ juvenile, however, these are more pronounced
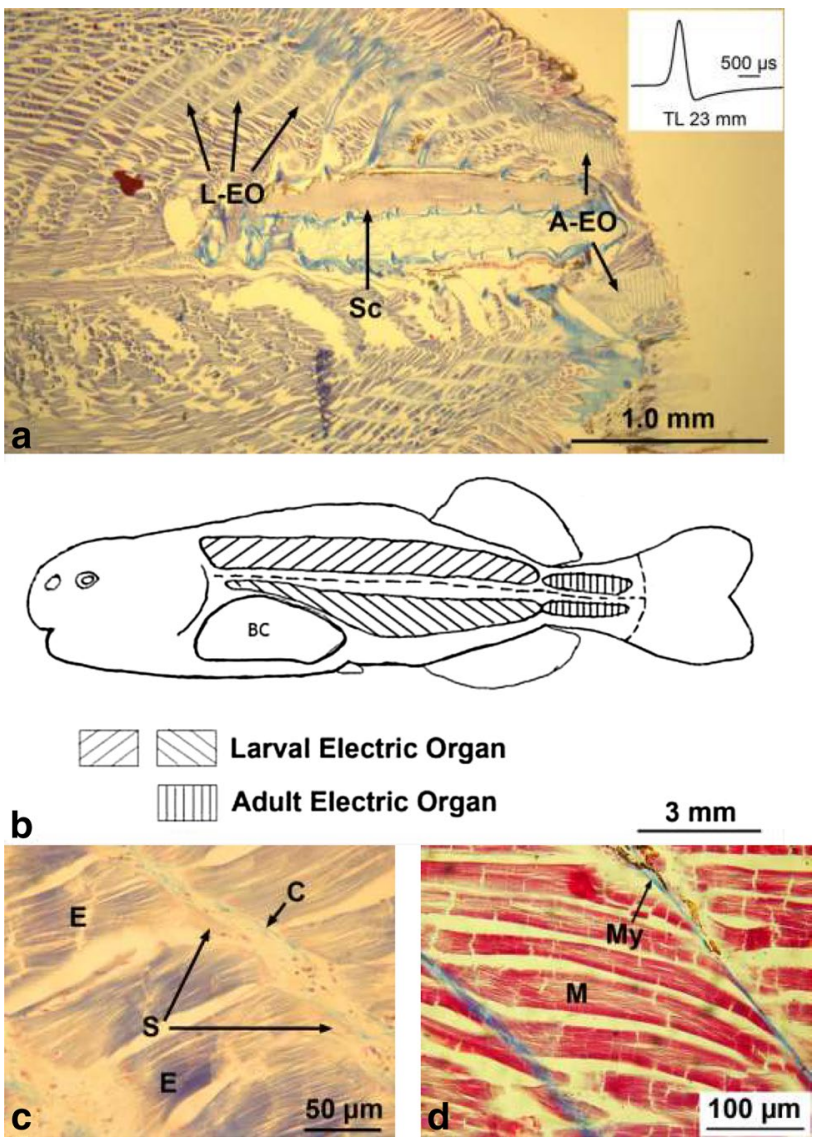

Fig. 6 Some characteristics of both, larval and adult electric organ in a 23-mm-long larva of Campylomormyrus rhynchophorus. a Medial sagittal section showing the position of both electric organs (L-EO, larval electric organ; A-EO, adult electric organ). Note that most of the caudal peduncle has been cut off and that at this stage only the L-EO is active (see inset). b Schema of the extension of the L-EO in the deep lateral muscle and of the A-EO in the caudal peduncle. c Photomicrograph of a Azan-stained sagittal section showing a few electrocytes (E) of the larval electric organ with their caudad stalk (S) extending into the space filled with loose connective tissue (C). Note the striation of the myofibrils. d Photomicrograph of a Azanstained sagittal section showing a few muscle fibers (M) attached to the myosepts (My)

at the periphery (Fig. 9c) than in the central part of the electrocyte (Fig. 9d). In a juvenile of $80 \mathrm{~mm}$ length, these papillae are even more densely packed at the periphery (Fig. 9e) than in the younger juvenile (Fig. 9c); again the central part of the electrocyte shows less developed papillae. The $155 \mathrm{~mm}$ juvenile also shows less developed papillae in the central part of the electrocyte (Fig. 9h), as compared to the periphery (Fig. $9 \mathrm{~g}$ ). At this stage, the peripheral papillae have a different form, extend even longer from the central axis of the electrocyte and contain a violet-stained center which seems to be composed of myofibrils. These run, similarly stained, through the whole 
Fig. 7 Photomicrographs of Azan-stained cross sections of the adult electric organ (EO) of four developmental stages (30, 34, 65, and $71 \mathrm{~mm}$ long) in Campylomormyrus rhynchophorus. Nerve fibers (n) from electromotoneurons situated in the spinal cord extend into the column of electrocytes and slightly bifurcate in both dorsal and ventral direction. The stalk system (s) is highly branched comprising one main stalk (ms) from which many branches (s) originate. a In this cross section the main stalk (ms) is covered by nerve fibers (n). b The central main stalk (ms) is clearly seen in this section. $\mathbf{c}$ The bifurcation of the main stalk dorsally and ventrally is particularly well seen in this section. $\mathbf{d}$ Note the very fine ramifications of the peripheral stalk system. vc, vertebral column
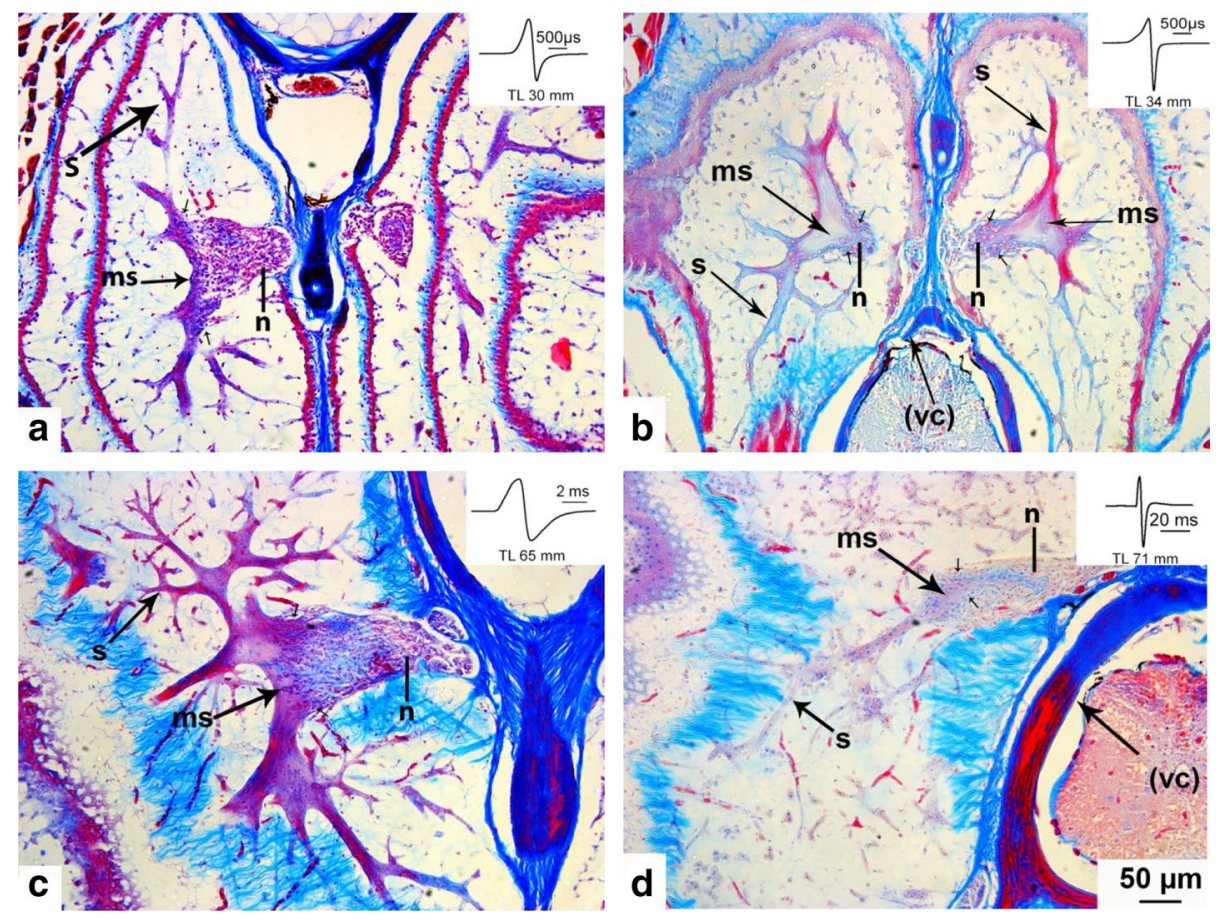

Table 2 Change of the different phases (P1-P3, see Fig. 5) of the electric organ discharge during ontogeny in Campylomormyrus rhynchophorus

\begin{tabular}{|c|c|c|c|c|}
\hline Size of fish & P1 duration (ms) & $\mathrm{P} 2$ duration (ms) & P3 duration (ms) & Total duration (ms) \\
\hline 33-37 mm TL & $0.47-0.51(\mathbf{0 . 4 9})$ & $0.41-0.56(\mathbf{0 . 5 0})$ & & $0.92-1.07$ (0.99) \\
\hline $50-59 \mathrm{~mm} \mathrm{TL}$ & $1.08-1.41(\mathbf{1 . 2 6})$ & $1.11-2.72(\mathbf{1 . 9 9})$ & & $2.71-4.09$ (3.25) \\
\hline $60-64 \mathrm{~mm} \mathrm{TL}$ & $1.79-2.41(\mathbf{2 . 0 7})$ & $3.44-4.59(\mathbf{3 . 9 9})$ & & $5.47-7.11(6.26)$ \\
\hline $64-69 \mathrm{~mm} \mathrm{TL}$ & $2.35-3.17(\mathbf{2 . 7 6})$ & $3.93-4.75$ (4.29) & $17.08-19.51(\mathbf{1 7 . 9 3})$ & $23.40-26.90(\mathbf{2 4 . 9 9})$ \\
\hline 91-104 mm TL & $3.67-4.69(\mathbf{3 . 9 2})$ & $4.53-4.86$ (4.75) & $28.65-32.36(\mathbf{3 0 . 9 5})$ & $37.24-41.68$ (39.62) \\
\hline $150-159 \mathrm{~mm}$ TL & $4.22-4.75(\mathbf{4 . 4 7})$ & $4.71-5.32(\mathbf{5 . 0 1})$ & $20.81-23.19(\mathbf{2 1 . 8 4})$ & $29.87-32.62(\mathbf{3 1 . 0 5})$ \\
\hline $320-380 \mathrm{~mm}$ TL & $3.60-4.55(\mathbf{4 . 1 7})$ & $4.07-4.97(\mathbf{4 . 6 1})$ & $13.73-18.13(\mathbf{1 5 . 2 6})$ & $22.53-26.51(\mathbf{2 4 . 0 4})$ \\
\hline
\end{tabular}

Mean values are in bold
Table 3 Number of electrocytes in the four columns of the electric organ in four stages of juvenile and early adult Campylomormyrus rhynchophorus

\begin{tabular}{lllll}
\hline Size of fish & $\begin{array}{l}\text { No. of E in } \\
\text { DR column }\end{array}$ & $\begin{array}{l}\text { No. of E in } \\
\text { DL column }\end{array}$ & $\begin{array}{l}\text { No. of E in } \\
\text { VR column }\end{array}$ & $\begin{array}{l}\text { No. of E in } \\
\text { VL column }\end{array}$ \\
\hline $32 \mathrm{~mm}$ & 48 & 50 & 48 & 47 \\
$36 \mathrm{~mm}$ & 49 & 48 & 42 & 46 \\
$65 \mathrm{~mm}$ & 46 & 46 & 44 & 47 \\
$80 \mathrm{~mm}$ & 44 & 46 & 42 & - \\
$155 \mathrm{~mm}$ & 51 & 52 & 51 & 50 \\
\hline
\end{tabular}

$E$ electrocyte, $D R$ dorsal right; $D L$ dorsal left, $V R$ ventral right, $V L$ ventral left

center of the electrocyte, which is a typical feature of the mormyrid electrocyte (see, e.g., Bruns 1971).

There are some structural features of the electrocytes of $C$. rhynchophorus which are atypical for electrocytes of mormyrid fish. Some electrocytes contain holes, short interruptions of the cell body, which are less numerous in the small fish, but seem to increase in number during ontogeny (Fig. 10a, b), compared to the largest individual (Fig. 10g, h). First in the $65 \mathrm{~mm}$ juvenile, we observed electrocytes in which the central element of the electrocyte widens, thus separating the rostral from the caudal face (Fig. 10c-f). Thereby a kind of cavity develops. Interestingly, the central band of myofibrils often terminates both at the dorsal or ventral face of that cavity (Fig. 10d, f). Whether these cavities later develop into holes, i.e., complete perforations of the cell, is not clear.

In the $15.5 \mathrm{~cm}$ fish we have based on the serial sagittal sections performed a first analysis concerning the distribution and the shape of the wholes in the center of the left dorsal column of electrocytes (52 electrocytes, see Table 3): the electrocytes in their dorso-ventral extension measure ca. $4 \mathrm{~mm}$. The wholes in different electrocytes are randomly 
Fig. 8 Photomicrographs of Azan-stained sagittal sections showing irregular geometry of some electrocytes in three stages $(32,36$, and $155-\mathrm{mm}$ long juveniles) of Campylomormyrus rhynchophorus. These electrocytes are attached either at the dorsal or the ventral face (a, c) of the electrocyte column but they do extend over the whole width of the column (b, d, e, f). $E$ electrocyte, $s$ stalk, $a f$ anterior face, $p f$ posterior face, $c$ connective tissue, $p$ papillae
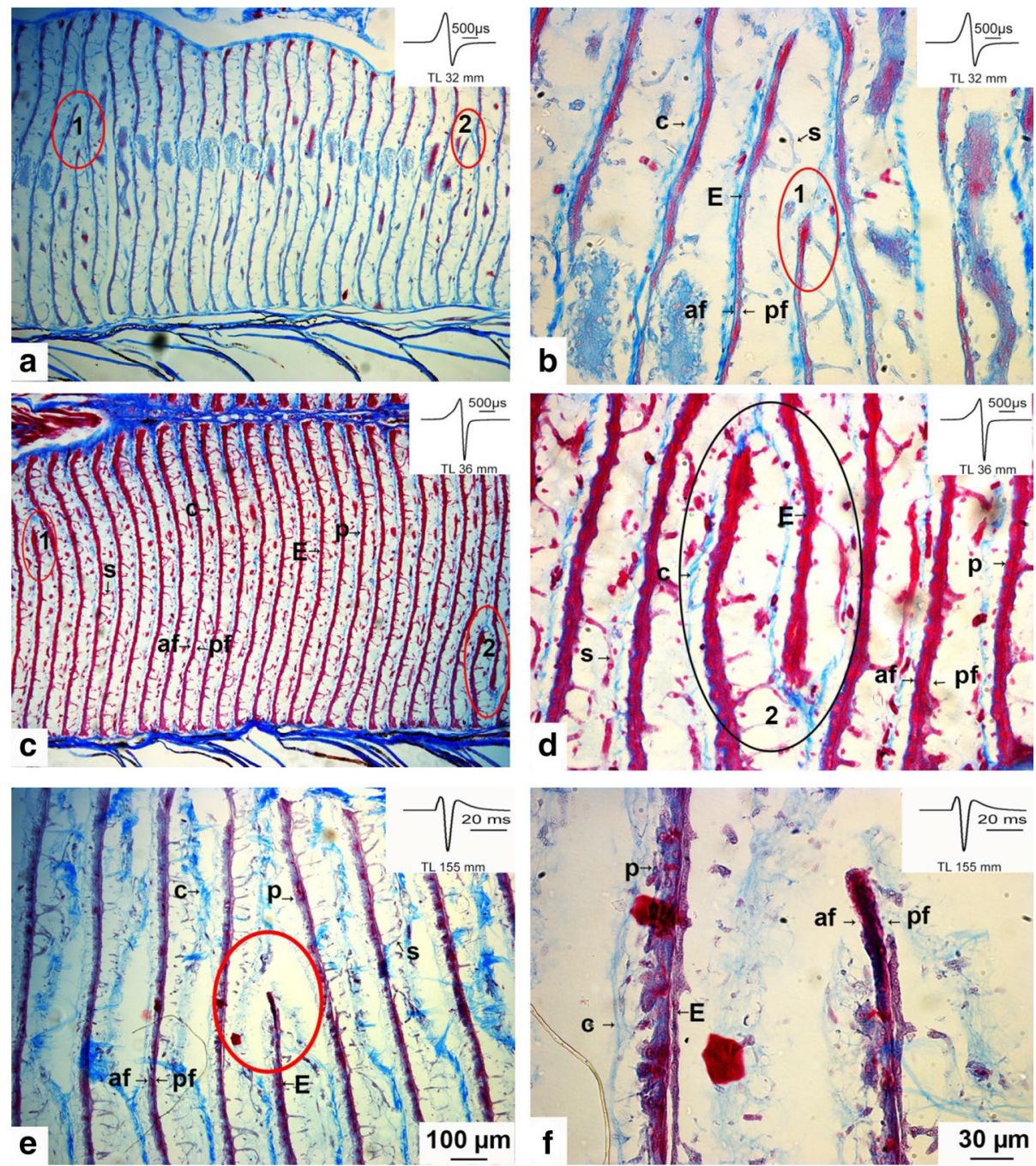

distributed over the whole length of the $4 \mathrm{~mm}$. The maximum opening of the wholes in the dorso-ventral extension is about $500 \mu \mathrm{m}$; their width in the lateral extension is about $100-250 \mu \mathrm{m}$.

\section{Discussion}

The aim of this study was a longitudinal description of the ontogeny of the adult electric organ of $C$. rhynchophorus which produces as adult an EOD of very long duration (ca. $25 \mathrm{~ms}$ ). We could indeed show (for the first time in a mormyrid fish) that the EOD which is produced early during ontogeny in juvenile fish is much shorter in duration and has a different shape than the adult EOD. The change from this juvenile EOD into the adult EOD is a long lasting process of at least a year. Some explanation for the increase in EOD duration could be the development of surface evaginations, papillae, at the rostral face of the electrocyte during ontogeny. We will discuss these findings based on the assumption that both anatomical and physiological changes contribute to these ontogenetic EOD changes.

\section{Larval electric organ}

The EOD of the larval electric organ of $C$. rhynchophorus is similar to that described in other mormyrid species, e.g., in the Pollimyrus species (Westby and Kirschbaum 1977; Baier et al. 2006) and in M. macrolepidotus (Werneyer and Kramer 2006). Also the anatomy of the larval electrocytes (shape, stalk) is similar to those described in P. isidori (Kirschbaum 1981) and other mormyrid species (H. bebe, M. rume, M. deliciosus, Kirschbaum 1995). The larval electric organ degenerates (Kirschbaum 1981) after the activation of the adult electric organ. We do not have histological data proving a degeneration in C. rhynchophorus; however, our EOD data of pure adult electric organ discharge beyond a certain developmental stage support the conclusion that the larval EO has degenerated throughout ontogeny. 
Fig. 9 Photomicrographs of Azan-stained sagittal sections of some electrocytes (E) to show papillae-like structures in four stages $(36,65,80$, and $155-\mathrm{mm}$ long juveniles) of Campylomormyrus rhynchophorus. The four pictures in the left column show the periphery of the $\mathrm{E}$, whereas those in the right column are taken from the center of the E. The papillae are more pronounced at the periphery $(\mathbf{a}, \mathbf{c}$, $\mathbf{e}, \mathbf{g})$ than in the center $(\mathbf{b}, \mathbf{d}, \mathbf{f}$, h) of the E. af anterior face, $C$ connective tissue, $E$ electrocyte, $p$ papillae, $p f$ posterior face, $S$ stalk
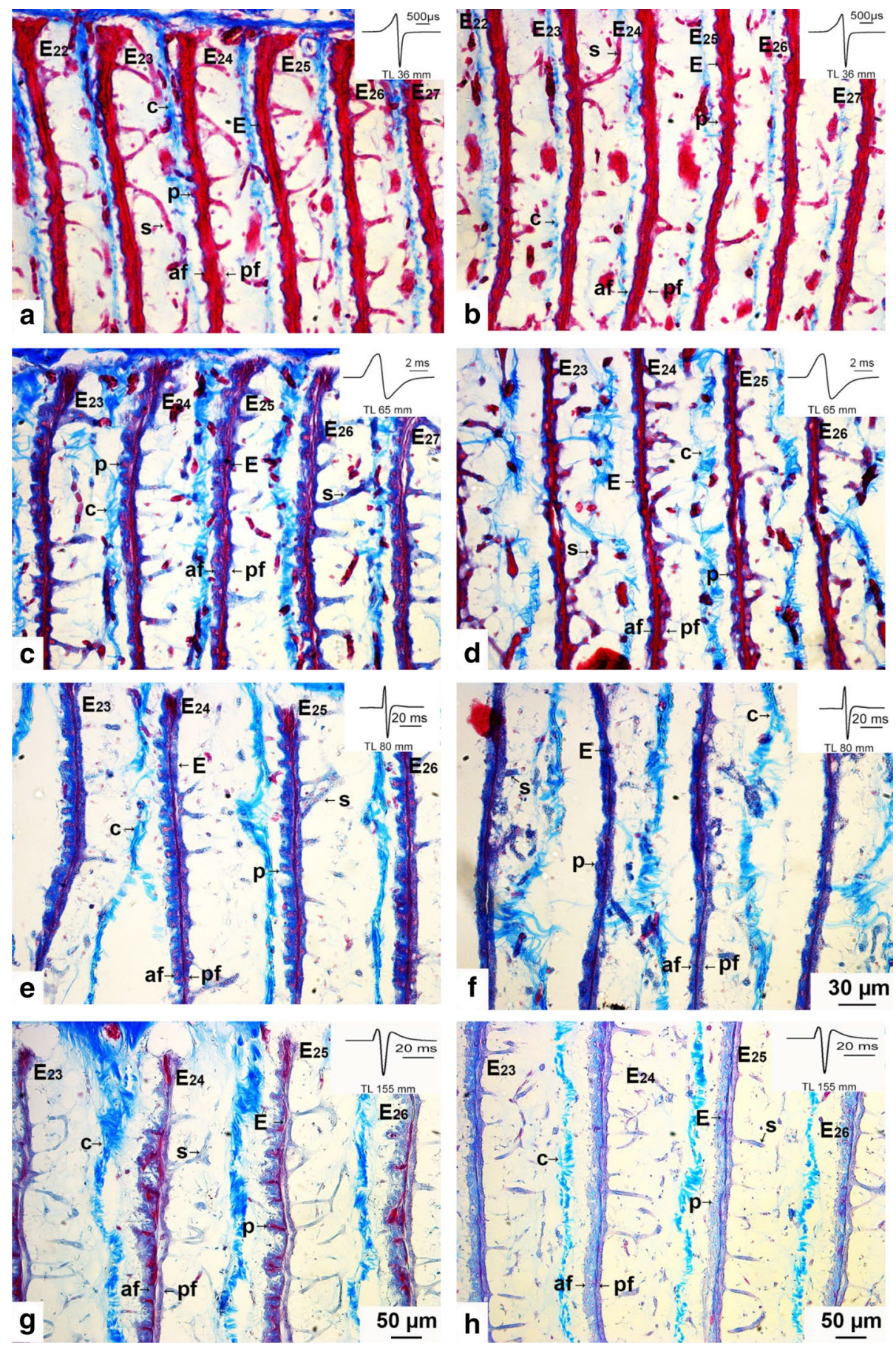

\section{Adult electric organ}

In $C$. rhynchophorus, early during ontogeny there is a transitional stage when the EODs of the larval electric organ and those of the adult electric organ are superimposed. This is similar to data from Marcusenius macrolepidotus (Werneyer and Kramer 2006). After this short transitional stage, only the adult EO is active, but its discharge in the juvenile $C$. rhynchophorus differs considerably from that in the adult, both in shape and duration. These changes occur gradually throughout at least a year. This pattern differs from that of M. macrolepidotus where the juvenile EOD does not change during ontogeny, but stays constant up to adulthood without any change in shape or duration. The EOD of M. macrolepidotus is biphasic with a headpositive phase followed by a head-negative phase of similar amplitude and duration, and is terminated by a very weak head-positive postpotential. The total duration of 
Fig. 10 Photomicrographs of Azan-stained sagittal sections of electrocytes (E) exhibiting holes and cavities in three developmental stages $(65,80$, and $155 \mathrm{~mm}$ long) of Campylomormyrus rhynchophorus. a, b Red oval encompasses an electrocyte (E) portion where the central myofilament bundle is interrupted or where a small cavity has developed (b). c, d Red ovals indicate locations, where cavities have developed. e Red oval encompasses E with a complete separation of upper and lower portion of the E (hole). f Hole number 2 (see e) at higher magnification. Note the alignment of the connective tissue along the E. af anterior face, $c$ connective tissue, $E$ electrocyte, $p f$ posterior face, $s$ stalk
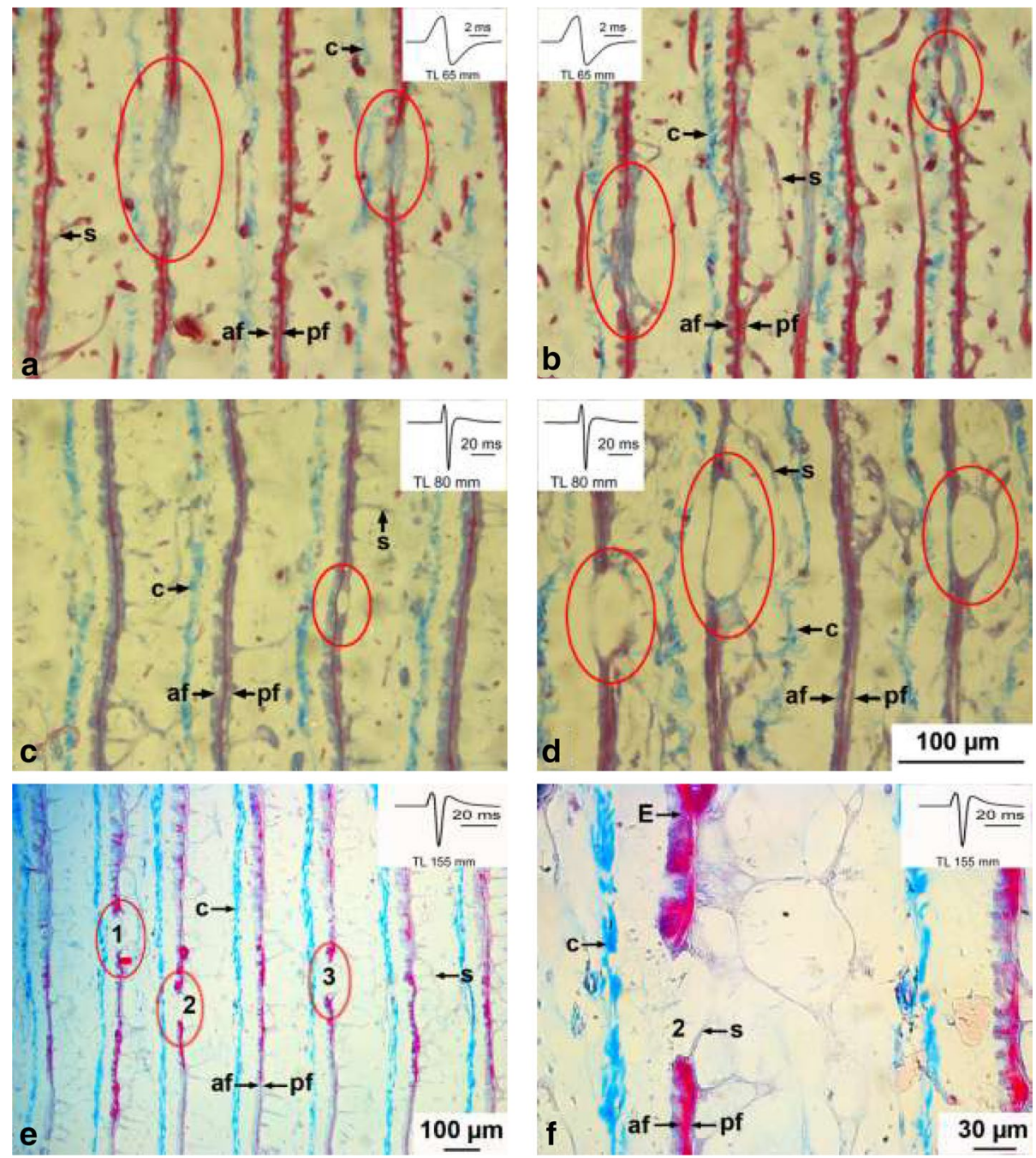

this EOD amounts to about $700 \mu$ s (Werneyer and Kramer 2006).

In principle, physiological and/or anatomical features could contribute to such a considerable ontogenetic change of the EOD in C. rhynchophorus. We show that the electrocytes of $C$. rhynchophorus develop during ontogeny surface proliferations on the rostral face (i.e., papillae) which could well be responsible for the increase in the total duration of the EOD, as already discussed by Paul et al. (2015) for $C$. numenius and by Bass et al. (1986) for Brienomyrus brachyistius [long biphasic) (later identified as Paramormyrops kingsleyae (Hopkins et al. 2007)]. Schwartz et al. (1975) made a calculation concerning the increase of surface area due to papillae: papillae $100 \mu \mathrm{m}$ in diameter and $150 \mu \mathrm{m}$ long can lead to a total increase of surface area by a factor of about 110 . We have described the papillae using a light microscope. A more detailed fine structural description (EM techniques) of these structures would be useful. Increase of surface area can also be obtained by tubular surface invaginations (Schwartz et al. 1975; Bass et al. 1986). Our light microscopical investigations do not reveal, whether such invaginations are present in C. rhynchophorus.

Holes and cavities in electrocytes are more prominent in the older stages of $C$. rhynchophorus. Our ontogenetic sequence suggests that the cavities might later on develop into the holes (Fig. 10e-f). It may be possible, that these holes contribute to some extent to the increase in EOD duration in juveniles longer than $10 \mathrm{~cm}$ (Fig. 5). The holes would delay the establishment of a potential across the electrocyte membrane due to a leakage of ions. Holes and irregularities in the electrocyte anatomy (Fig. 8) are different structures which can be deduced from the course of the connective tissue sheath surrounding the individual electrocytes (compare Figs. 8 and 10). We cannot see how the few irregular electrocytes could have an influence on EOD duration or shape.

During ontogeny, the EOD of $C$. rhynchophorus changes from a biphasic into a triphasic EOD, while the basic geometry of the electrocytes does not change: the main stalk is located at the caudal face and penetrations are absent. One explanation could be that the activation of the rostral by the caudal face 
(Bennett 1971) is pertained for a long time, thus exceeding the duration of the activation of the caudal face. Such a triphasic EOD of about $200 \mu$ s duration is, e.g., produced by $P$. isidori (Westby and Kirschbaum 1982), a species which does not possess papillae (Denizot et al. 1982).

In Fig. 4, we show that the inter-individual variation of the EOD both concerning shape and duration is very small. The largest individual variation is seen in the 60- to 64-mm-long fish (Fig. 4d). At this stage, the papillae become more prominent (Fig. 9). These individual variations in EOD may relate to individual differences in the differentiation of the papillae. Regarding potential physiological parameters underlying the ontogenetic change in EOD seen in C. rhynchophorus, Nagel et al. (2017) correlated the long EOD of $C$. tshokwe ( $4 \mathrm{~ms}$ as compared to the short EOD of $C$. compressirostris of about $200 \mu$ s duration) with a significantly elevated expression of voltage-gated ion channel genes in $C$. tshokwe. The juvenile EODs of both species, however, are nearly identical (Kirschbaum et al. 2016; Nguyen et al. 2017). Therefore, the differential expression apparently is not yet established in the early juvenile of $C$. tshokwe. If a similar scenario would be valid for $C$. rhynchophorus, the ontogenetic change in the shape of the EOD could also be correlated with an ontogenetic increase in the expression of voltage-gated ion channel genes. This hypothesis, however, remains to be tested, which seems well feasible, as $C$. rhynchophorus can be bred quite easily in captivity. It is quite probable that physiological developmental changes also relate to the observed morphological changes of the electrocyte membrane. A potential candidate for the explanation of EOD changes during ontogeny could also be the kcna7a channel gene which is predominantly expressed in mormyrid electric organs (Immani et al. 2018).

In this paper, we describe the whole ontogenetic sequence from the early juvenile up to the adult fish. Interestingly, the EOD typical for the adult was produced by the fish for the first time when they had reached the minimum size for first sexual maturity, i.e., at a length of about $15 \mathrm{~cm}$. This is to be expected, as the adult EOD is used in the context of reproductive behavior and has relevance for reproductive isolation of sympatric closely related species (Feulner et al. 2008; Nagel et al. 2018a, b).

The adult EOD as a tool for species identification is robust in species with no ontogenetic changes in EOD. In species with ontogenetic changes of EOD, as in C. rhynchophorus or C. numenius (Paul et al. 2015), juvenile EODs erroneously taken as species identification tool can lead to misidentification of species.

\section{Conclusions}

The change in shape and duration of the EOD in $C$. rhynchophorus can to a certain extent be explained by structural changes of the electrocytes during ontogeny. Our light microscopical studies provide a first description of the anatomy of the papillae. Further electron microscopical studies (both transmission and scanning techniques) would be useful to increase our knowledge in this respect, if applied in a comparative way across differentially discharging species/ ontogenetic stages in the genus Campylomormyrus.

Acknowledgements We thank S. Abelt for technical assistance and $\mathrm{H}$. Höft for occasionally taking care of the fish. Financial support is acknowledged from the University of Potsdam and the Leibniz-SAW project GENART. We thank two unknown reviewers for their valuable comments on the manuscript. All applicable international, national, and/or institutional guidelines for the care and use of animals were followed.

Funding Open Access funding enabled and organized by Projekt DEAL.

Open Access This article is licensed under a Creative Commons Attribution 4.0 International License, which permits use, sharing, adaptation, distribution and reproduction in any medium or format, as long as you give appropriate credit to the original author(s) and the source, provide a link to the Creative Commons licence, and indicate if changes were made. The images or other third party material in this article are included in the article's Creative Commons licence, unless indicated otherwise in a credit line to the material. If material is not included in the article's Creative Commons licence and your intended use is not permitted by statutory regulation or exceeds the permitted use, you will need to obtain permission directly from the copyright holder. To view a copy of this licence, visit http://creativecommons.org/licenses/by/4.0/.

\section{References}

Arnegard ME, Bogdanowicz SM, Hopkins CD (2005) Multiple cases of striking genetic similarity between alternate electric fish signal morphs in sympatry. Evolution 59:324-343

Baier B, Lamml M, Kramer B (2006) Ontogeny of electric organ discharge in two parapatric species of the dwarf stonebasher Pollimyrus castelnaui and P. marianne (Mormyridae, Teleostei). Acta Zool 87:209-214

Balon EK (1975) Terminology of intervals in fish development. J Fish Res Board Can 2:1663-1670

Bass AH (1986) Species differences in electric organs of mormyrids: Substrates for species-typical electric organ discharge waveforms. J Comp Neurol 244:313-330

Bass AH, Denizot J-P, Marchaterre MA (1986) Ultrastuctural features and hormone-dependent sex differences in mormyrid electric organs. J Comp Neurol 254:511-528

Bennett MVL (1970) Comparative Physiology: Electric Organs. Ann Rev Physiol 32(1):471-528

Bennett MVL (1971) Electric organs. In: Hoar WS, Randall DJ (eds) Fish physiology, vol V. Academic Press, London, pp 347-491

Bruns V (1971) Elektrisches Organ von Gnathonemus (Mormyridae)elektrische Platte und Innervation. Z Zellforsch 122:538-563. https://doi.org/10.1007/BF00936087

Bullock TH, Heiligenberg W (1986) Electroreception. John Wiley \& Sons, New York

Crampton WGR (2006) Evolution of electric signal diversity in gymnotiform fishes II. Signal design. In: Ladich F, Collin SP, Moller P, Kapoor BG (eds) Communication in fishes. Science Publishers, Enfield, pp 697-731 
Crampton WGR, Rodriguez-Cuttaneo Lovejoy NR, Caputi AA (2013) Proximate and ultimate causes of signal diversity in the electric fish Gymnotus. J Exp Biol 216:2523-2541

Denizot JP, Kirschbaum F, Westby GWM, Tsuji S (1978) The larval electric organ of the weakly electric fish Pollimyrus (Marcusenius) isidori (Mormyridae, Teleostei). J Neurocyt 7:165-181

Denizot JP, Kirschbaum F, Westby GWM, Tsuji S (1982) On the development of the adult electric organ in the mormyrid fish Pollimyrus isidori (with special focus on the innervation). J Neurocyt 11:913-934. https://doi.org/10.1007/BF01148308

Feulner PGD, Plath M, Engelmann J, Kirschbaum F, Tiedemann R (2008) Electrifying love: electric fish use species-specific discharge for mate recognition. Biol Lett. https://doi.org/10.1098/ rsbl.2008.0566

Froese R, Pauly D (2008) Fish Base. World Wide Web electronic publication. http://www.fishbase.org

Hopkins CD (1981) On the diversity of electric signals in a community of mormyrid electric fish in West Africa. Amer Zool 21:211-222. https://doi.org/10.1093/icb/21.1.211

Hopkins CD, Lavoué S, Sullivan JP (2007) Mormyridae. In: Stiassny MLJ, Teugels GG, Hopkins CD (eds). The fresh and brackish water fishes of Lower Guinea, West-Central Africa. Volume I. Collection Faune et Flore tropicales 42. Institut de Recherche pour le Développement, Paris, France, Muséum National d'Histoire Naturelle, Paris, France, and Musée Royal de l'Afrique Centrale, Tervuren, Belgium. pp. 219-334

Immani S, Ghezzi A, York JM, Markham MR, Halling DB, Lu Y, Gallant JR, Zakon HH (2018) Electrostatic tuning of a potassium channel in electric fish. Curr Biol 28:2094-2102

Keynes RD (1961) The development of the electric organ in Electrophorus electricus L. In: Chagas C, Carvalho A (eds) Bioelectrogenesis. Elsevier, Amsterdam, pp 14-19

Kirschbaum F (1975) Environmental factors control the periodical reproduction of tropical electric fish. Experientia 31(10):1159-1160

Kirschbaum F (1977) Electric-organ ontogeny:distinct larval organ precedes adult organ in weakly electric fish. Naturwissenschaften 64:387-388. https://doi.org/10.1007/BF00368748

Kirschbaum F (1981) Ontogeny of both larval electric organ and electromotoneurones in Pollimyrus isidori (Mormyridae, Teleostei). In: Szabo T, Czeh G (eds) Advances in physiological sciences vol 31 , sensory physiology of aquatic lower vertebrates. Akadémiai Kiadió, Budapest, pp 129-157

Kirschbaum F (1995) Reproduction and development in mormyriform and gymnotiform fishes. In: Moller P (ed) Electric fishes-history and behavior. Fish and fisheries series. Chapman and Hall, London, pp 267-301

Kirschbaum F, Westby GWM (1975) Development of the electric discharge in Mormyrid and Gymnotid fish (Marcusenius sp. and Eigenmannia virescens). Experientia 31:1290-1293

Kirschbaum F, Schwassmann HO (2008) Ontogeny and evolution of electric organs in gymnotiform fish. J Physiol (Paris) 102(4-6):347-356

Kirschbaum F, Nguyen L, Baumgartner S, Chi HWL, Wolfart R, Elarbani K, Eppenstein H, Korniienko Y, Mamonekene V, Vater M, Tiedemann R (2016) Intragenus (Campylomormyrus) and intergenus hybrids in mormyrid fish: physiological and histological investigations of the electric organ ontogeny. J Physiol 110:281-301

Koelliker R (1849) Über die elektrischen Organe des Mormyrus longipinnis Rüpp. Ber Zool Anst Würzburg 9-13

Kramer B (1990) Electrocommunication in teleost fishes: behavior and experiments. Springer, Berlin

Lamanna F, Kirschbaum F, Tiedemann R (2016) Species delimitation and phylogenetic relationships in a genus of African weakly electric fish (Oteoglossiformes, Mormyridae, Campylomormyrus). Mol Phylogenet Evol 101:8-18
Moller P (1995) Electric fishes: history and behavior, fish and fisheries series, vol 17. Chapman \& Hall, London

Mulisch M, Welsch U (2010) Romeis-Mikroskopische Technik, 18th edn. Spektrum, Heidelberg

Nagel R, Kirschbaum F, Tiedemann R (2017) Electric organ discharge diversification in mormyrid weakly electric fish is associated with differential expression of voltage-gated ion channel genes. J Comp Physiol A 203:183-195. https://doi.org/10.1007/ s00359-017-1151-2

Nagel R, Kirschbaum F, Hofmann V, Engelmann J, Tiedemann R (2018a) Electric pulse characteristics can enable species recognition in African weakly electric fish species. Sci Rep 8:10799. https://doi.org/10.1038/s41598-018-29132-z

Nagel R, Kirschbaum F, Engelmann J, Hofmann V, Pawelzik F, Tiedemann R (2018b) Male-mediated species recognition among African weakly electric fishes. R Soc Open Sci 5:170443. https://doi.org/10.1098/rsos.170443

Nguyen MDL, Paul C, Mamonekene V, Bartsch P, Tiedemann R, Kirschbaum F (2017) Reproduction and development in some species of weakly electric genus Campylomormyrus (Mormyridae, Teleostei). Environ Biol Fishes 100:49-68. https://doi.org/ 10.1007/s10641-016-0554-1

Paul C, Mamonekene V, Vater M, Feulner PGD, Engelmann J, Tiedemann R, Kirschbaum F (2015) Comparative histology of the adult electric organ among four species of the genus Campylomormyrus (Teleostei: Mormyridae). J Comp Physiol A 201:357-374

Schlichter H (1906) Über den feineren Bau des schwachen elektrischen Organs von Mormyrus oxyrhynchus. Z wiss Zool 84:478-525

Schugardt (1997) Experimentelle Untersuchungen zur exogenen Kontrolle der zyklischen Fortpflanzung afrikanischer Süßwasserfische: Vergleich von Mormyriden und Polypterus. Dissertation. Humboldt University Berlin. p 191

Schwartz IR, Pappas GD, Bennett MVL (1975) The fine structure of electrocytes in weakly electric teleosts. J Neurocytol 4:87-114

Szabo T (1958) Structure intime de l'organe electric de trois mormyrides. Z Zellforsch 9:33-45

Szabo T (1960) Development of the electric organ of mormyridae. Nature 188:760-762

Szabo T (1966) The origin of the electric organs of Electrophorus electricus. Anat Rec 155:103-110

von der Emde G (1992) Electrolocation of capacitive objects in four species of pulse-type weakly electric fish: II. Electric signalling behaviour. Ethology. 92:177-192

von der Emde G (1999) Active electrolocation of objects in weakly electric fish. J Exp Biol 202:1205-1215

von der Emde G (2006) Non-visual environmental imaging and object detection through active electrolocation in weakly electric fish. J Comp Physiol A Neuroethol Sens Neural Behav Physiol 192:601-612

Werneyer M, Kramer B (2006) Ontogeny development of electricorgan discharges in a mormyrid fish, the bulldog Marcusenius macrolepidotus (South African form). J Fish Biol 69:1190-1201

Westby GWM, Kirschbaum F (1977) Emergence and development of the electric organ discharge in the mormyrid fish, Pollimyrus isidori. I. The larval discharge. J Comp Physiol 122:251-271

Westby GWM, Kirschbaum F (1978) Emergence and development of the electric organ discharge in the mormyrid fish, Pollimyrus isidori. II. Replacement of the larval by the adult discharge. J Comp Physiol 127:45-59

Westby GWM, Kirschbaum F (1982) Sex differences in the waveform of the pulse-type electric fish, Pollimyrus isidori (Mormyridae). J Comp Physiol 145:399-403. https://doi.org/10.1007/BF00619344

Publisher's Note Springer Nature remains neutral with regard to jurisdictional claims in published maps and institutional affiliations. 